\section{Tracking the formation of magma oceans in the Solar System using stable magnesium isotopes}

\section{Schiller1*, J.A. Dallas', J. Creech², M. Bizzarro', J.A. Baker ${ }^{3}$}

\section{Abstract}

The processes associated with magma ocean formation and solidification can control the earliest compositional differentiation and volatile inventory of planetary bodies. Thus, elucidating the scale and extent to which magma oceans existed in the Solar System is critical for a full understanding of planet formation. Here we show that the magnesium isotope compositions of the co-magmatic diogenite and eucrite meteorites originating from the protoplanet Vesta are distinct and this is a predictable consequence of extensive crystallisation in a shallow magma ocean. The enrichment in the heavy magnesium isotopes observed in eucrites relative to diogenites is consistent with the isotopic differences measured between minerals and whole-rock basalts on Earth and other asteroids. This isotope effect is not readily observed on Earth due to the lower primary melt magnesium contents produced res at smaller degrees of melling and less extenswe amounts of mafic mineral crystallisation. crystallised and, thus, $\mathrm{Mg}$ isotopes provide a tracer of their previous existence.

Received 1 June 2016 | Accepted 15 August 2016 | Published 1 September 2016

\section{Introduction}

Magma oceans are widely considered to have existed on planetary bodies in the early Solar System, given the monominerallic nature of much of the lunar crust (Wood et al., 1970) and extremely ancient ages obtained for lunar, martian and asteroidal igneous rock (e.g., Debaille et al., 2007; Nemchin et al., 2009; Schiller et al. 2011). These may have been produced by planetary scale melting induced by heating of short-lived ${ }^{26} \mathrm{Al}$ in the case of early-formed protoplanets such as

. Centre for Star and Planet Formation, University of Copenhagen, Øster Voldgade 5-7,1350 Copenhagen, Denmark

Corresponding author (email: schiller@snm.ku.dk)

2. Institut de Physique du Globe de Paris, Université Paris Diderot, CNRS UMR 7154, 75005 Paris, France

3. School of Environment, The University of Auckland, Private Bag 92019, Auckland, New Zealand

Vesta (Greenwood et al., 2005), or giant impacts such as the Moon-forming event in the case of the Earth and Moon (Tonks and Melosh, 1993). As such, finding robust geochemical fingerprints of these ancient magma oceans is important for understanding the earliest stages of planetary evolution.

A range of newly developed stable isotope systems are yielding novel insights into planetary accretion, differentiation and evolution (e.g., Greenwood et al., 2005; Georg et al., 2007). However, many of these systems are multiply affected by a range of processes, potentially including core formation and crystallisation of accessory minerals, which makes interpretation of such data challenging. The lithophile, major element magnesium $(\mathrm{Mg})$ is almost unique in this regard, as stable isotope fractionation in magmatic systems will be almost entirely controlled by crystallisation of high- $\mathrm{Mg}$, mafic minerals, assuming isotopic fractionations exist between such minerals and magma.

The large degree of planetary melting required to generate a magma ocean would produce highly magnesian magmas, which would then subsequently crystallise large amounts of mafic, Mg-rich minerals such as olivine. Small Mg stable isotope fractionations exist between co-existing terrestrial mantle olivine, orthopyroxene and clinopyroxene, with olivine being the isotopically lightest phase (Handler et al., 2009; Young et al., 2009; Pogge von Strandmann et al., 2011; Xiao et al., 2013). Consequently, it should also be possible to detect progressive $\mathrm{Mg}$ isotope changes in the products of a crystallising magma ocean.

Vesta is the second largest asteroid in the Solar System and comprises a metal core, silicate mantle and crust (Russell et al., 2012). Based on spectral observations and the Dawn Mission, the howardite-eucrite-diogenite (HED) meteorite suite is inferred to come from Vesta (McCord et al., 1970; Binzel and Xu, 1993; Russell et al., 2012). Most HED meteorites also share common nucleosynthetic isotope signatures for some elements that demonstrate their genetic affinity (Greenwood et al., 2005). These lithologically diverse meteorites provide a unique archive of the timing and processes of protoplanet formation and differentiation. Diogenites are mostly orthopyroxenites, and are conventionally viewed as cumulate igneous rocks formed in a magma ocean or bodies on Vesta, whereas eucrites are basaltic and gabbroic rocks predominantly composed of pigeonite and plagioclase (Mittlefehldt, 2014)

Despite many decades of petrological, geochemical and chronological study, the petrogenesis of eucrites and diogenites and the relationship between them remain enigmatic. End-member models include limited partial melting or extensive (i.e. magma ocean) melting of Vesta (Stolper, 1977; Mandler and ElkinsTanton, 2013; Mittlefehldt, 2014). Nearly all models are difficult to reconcile with the large range of incompatible trace element concentrations in diogenites and eucrites. However, a recent study by Mandler and Elkins-Tanton (2013) has used both chemical and physical arguments to create a model that links HED lithologies to different stages of a differentiating global-scale magma ocean. 


\section{Mg Isotope Evidence for a Vestan Magma Ocean}

Insights into the degree of partial melting on Vesta can be gleaned from the major and trace element chemistry of the most primitive, oldest diogenites that have the largest deficits in radiogenic ${ }^{26} \mathrm{Mg}$ (Schiller et al., 2011) and features indicating crystallisation from melts with broadly chondritic rare earth element ratios (the full methodological approach is described in the Supplementary Information). Our modelling (Fig. 1) shows that diogenites crystallised as cumulates from $>50 \%$ partial melt of a chondritic precursor. This melt would have been part of either a global magma ocean (Mandler and Elkins-Tanton, 2013) or, given thermal modelling constraints, a more localised shallow magma ocean (Neumann et al., 2014). The diogenite parental magmas produced by such large degrees of melting of the vestan, post-core, silicate mantle are highly magnesian with ca. 19-33 wt. \% MgO (e.g., Ashcroft and Wood, 2015) and would undergo ca. $>50 \%-70 \%$ olivine and orthopyroxene crystallisation before the $\mathrm{MgO}$ content of the residual melt approaches that of eucrites. A stable Mg isotopic difference should exist between diogenites and eucrites if they are genetically related by large amounts of olivine and orthopyroxene crystallisation, and if there is a small isotopic fractionation between olivine-orthopyroxene and melt.

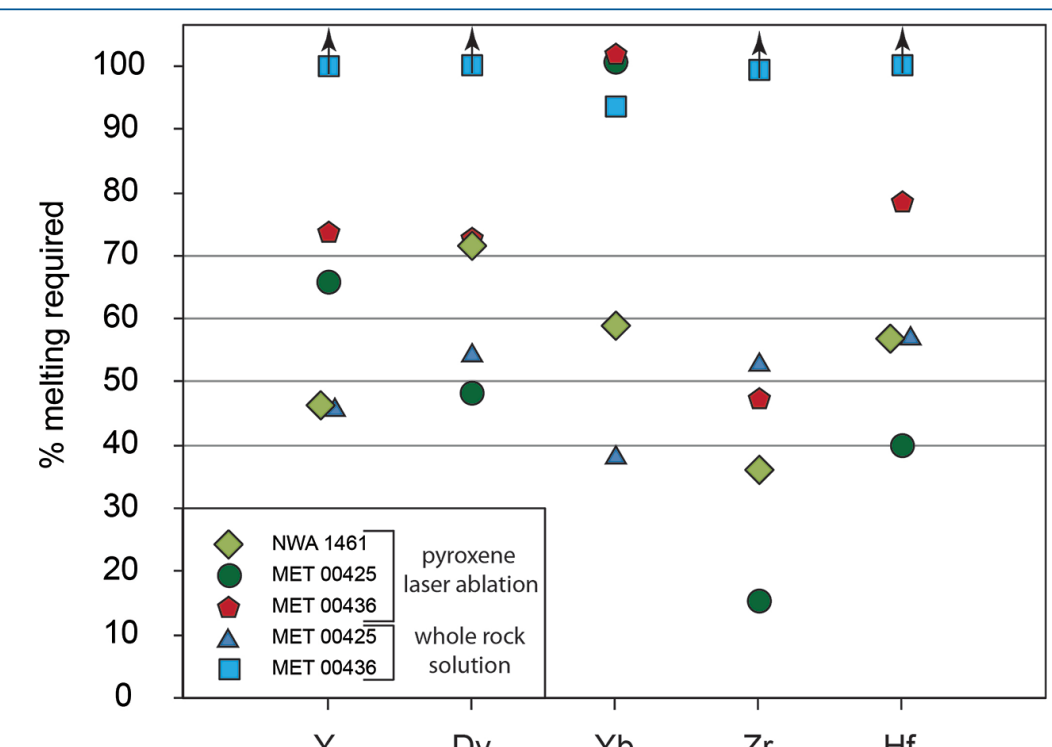

Figure 1 The minimum degree of partial melting of the vestan mantle, based on modelling the selected incompatible trace element contents of primitive diogenites. Calculations are based on trace element data for pyroxene determined by laser ablation ICP-MS (Schiller et al., 2011) or digestions of leached whole rock diogenites measured by solution ICP-MS (Barrat et al., 2010). Details of the partial melting model can be found in the Supplementary Information.
We present high-precision stable $\mathrm{Mg}$ isotope data for 22 eucrites determined by multiple-collector inductively coupled plasma mass spectrometry using well established analytical protocols (Table 1; see Supplementary Information for more details) and compare these with published $(\mathrm{n}=23)$ and new $(\mathrm{n}=2)$ values for 25 diogenites obtained with exactly the same analytical methods (Schiller et al., 2011 and this study). The mean Mg stable isotope composition

Table $1 \mathrm{Mg}$ stable isotope data for 22 eucrites, 2 diogenites and the terrestrial basalt standard BHVO-2 relative to the $\mathrm{Mg}$ standard DSM-3.

\begin{tabular}{|l|c|c|}
\hline \multicolumn{1}{|c|}{ Sample } & $\mu^{25} \mathrm{Mg}( \pm 2$ SE; ppm $)$ & $\mu^{26} \mathrm{Mg}( \pm 2 \mathrm{SE} ; \mathrm{ppm})$ \\
\hline Terrestrial basalt & & \\
BHVO-2 & $-133 \pm 20$ & $-252 \pm 38$ \\
\hline Polymict eucrites & \\
EET 83227 & $-105 \pm 6$ & $-180 \pm 10$ \\
\hline Mg-rich eucrites & & \\
EET 87548 & $-104 \pm 25$ & $-192 \pm 47$ \\
LEW 87002 & $-37 \pm 14$ & $-65 \pm 30$ \\
\hline Brecciated eucrites & & \\
Camel Donga & $+33 \pm 21$ & $+111 \pm 43$ \\
EET 92003 & $-41 \pm 12$ & $-52 \pm 24$ \\
GRA 98006 & $-67 \pm 10$ & $-88 \pm 18$ \\
GRA 98033 & $-83 \pm 13$ & $-124 \pm 25$ \\
GRA 98043 & $-63 \pm 14$ & $-89 \pm 27$ \\
GRA 98055 & $-70 \pm 25$ & $-111 \pm 39$ \\
GRA 98114 & $-83 \pm 18$ & $-61 \pm 25$ \\
GRO 95533 & $-54 \pm 13$ & $-174 \pm 7$ \\
Juvinas & $-106 \pm 4$ & $-96 \pm 24$ \\
LAP 031062 & $-60 \pm 12$ & $-26 \pm 32$ \\
LAR 06875 & $-34 \pm 17$ & $-76 \pm 65$ \\
Millibillilie & $-60 \pm 28$ & $-109 \pm 35$ \\
PCA 91193 & $-66 \pm 18$ & $-81 \pm 21$ \\
QUE 99005 & $-62 \pm 11$ & $-93 \pm 17$ \\
RKPA 80204 & $-66 \pm 9$ & $-29 \pm 20$ \\
SCO 06041 & $-21 \pm 11$ & $-156 \pm 11$ \\
\hline Unbrecciated eucrites & & $-74 \pm 28$ \\
EET 92023 & $-96 \pm 5$ & $-212 \pm 32$ \\
LEW 85035 & $-65 \pm 17$ & \\
QUE 97014 & $-55 \pm 14$ & \\
\hline Diogenites & & \\
Dhofar 700 & $-125 \pm 3$ & \\
NWA 4215 & & \\
\hline
\end{tabular}


for 22 eucrites is $\mu^{25} \mathrm{Mg}_{\mathrm{DSM}-3}=-62 \pm 13 \mathrm{ppm}$ (2 SE; Fig. 2), which is heavier than the mean of diogenites $\left[\mu^{25} \mathrm{Mg}_{\mathrm{DSM}-3}=-118 \pm 11 \mathrm{ppm}(2 \mathrm{SE})\right]$. A t-test shows that the isotopic difference between eucrites and diogenites is statistically significan $\left(\mathrm{p}=5.5 \times 10^{-8}\right)$. Diogenites have stable $\mathrm{Mg}$ isotopes that are indistinguishable from those for Earth's mantle and chondrite meteorites, although within the heavier range for these materials. In contrast, eucrites are isotopically heavier than all these materials (Fig. 2).

Figure 2 Stable $\mathrm{Mg}$ isotope composition $\left(\mu^{25} \mathrm{Mg}\right.$, where $\mu^{25} \mathrm{Mg}$ $=\left[\left({ }^{25} \mathrm{Mg} /{ }^{24} \mathrm{Mg}\right)_{\text {sample }} /\left({ }^{25} \mathrm{Mg} /{ }^{24} \mathrm{Mg}\right)\right.$ DSM-3 -1$\left.] \times 10^{6}\right)$ of diogenites and eucrites (Schiller et al., 2011 and this study), phenocryst olivine and groundmass from the angrite meteorite NWA 1670 (Schiller et al., 2015), and Hawaiian basalts and olivine phenocrysts least affected by $\mathrm{Mg}$-Fe inter-diffusion based on their Fe stable isotope composition (Teng et al., 2011 and references therein). The bottom of the figure shows the probability density distribution of each group and the results of t-testing. The external reproducibility reported for each respective study or the internal error, whichever was larger, was used for the calculation of the probability density distributions and t-testing. Also shown are the ranges of the $\mathrm{Mg}$ stable isotope compositions of Earth's mantle (Teng et al., 2010) and chondrites (Teng et al., 2010; Larsen et al., 2016), as well as the average $\mu^{25} \mathrm{Mg}$ of olivine, orthopyroxene and clinopyroxene in Earth's mantle (Handler et al., 2009; Young et al., 2009; Pogge von Strandmann et al., 2011; Xiao et al., 2013).

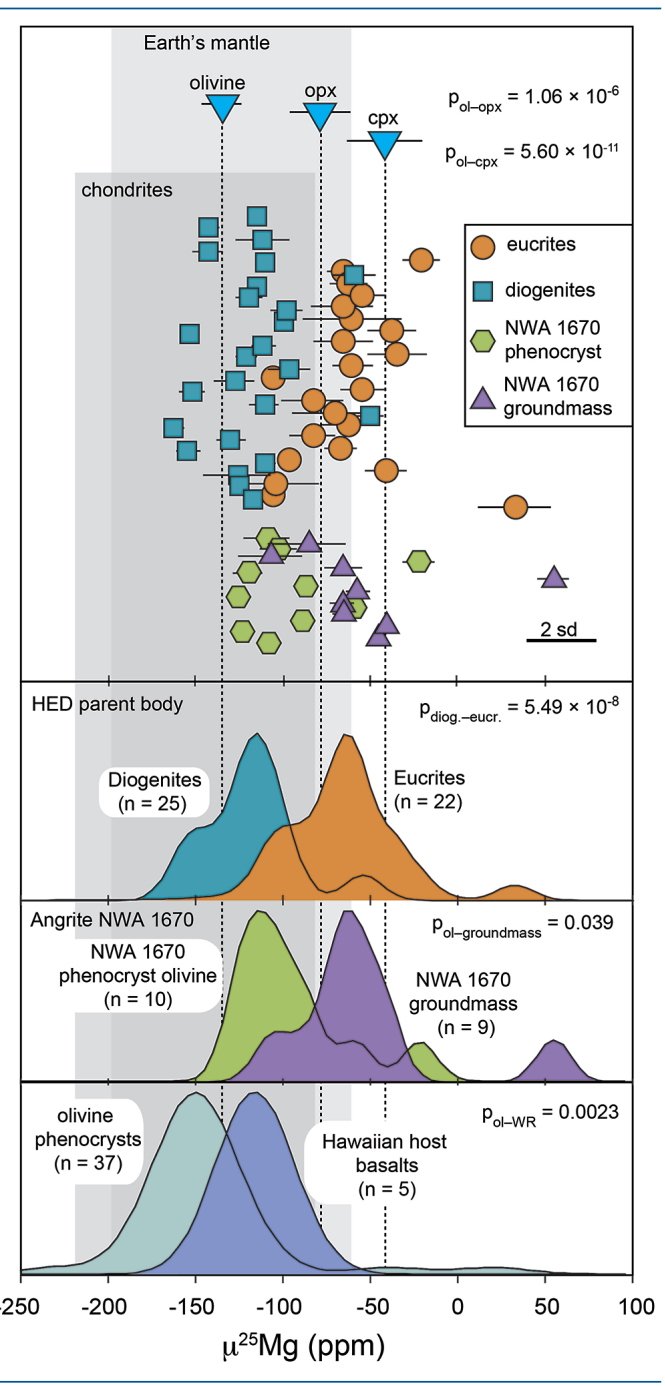

Before attributing the stable $\mathrm{Mg}$ isotope difference between diogenites and eucrites to magmatic processes, it is necessary to consider other processes that might explain this. Firstly, diffusion in magmatic systems can fractionate $\mathrm{Mg}$ and iron (Fe) isotopes (Teng et al., 2011), which generates a negative correlation between $\mathrm{Mg}$ and Fe stable isotopes, with $\mathrm{Fe}$ isotopes being more sensitive to this process than $\mathrm{Mg}$ isotopes in Mg-rich olivine. This is inconsistent with the eucrite data, given that eucrites have heavy $\mathrm{Mg}$ compared to diogenites but indistinguishable Fe isotope compositions (Wang et al., 2012). Furthermore, diogenites have a light $\mathrm{Mg}$ isotope composition when compared to eucrites, which is opposite to the prediction of a heavy $\mathrm{Mg}$ isotope composition of olivine and pyroxene resulting from inter-diffusion with a melt (Fig. 2). Secondly, small stable Mg isotope differences exist between mafic minerals (Fig. 2) and, as such, mineralogical differences between diogenites and eucrites might explain their wholerock stable isotope offset. However, given that low-Ca pyroxene is the dominant host of $\mathrm{Mg}$ in both diogenites and eucrites, the isotope offset between eucrites and diogenites is too large to reflect solely mineralogical differences. Thus, we attribute the stable $\mathrm{Mg}$ isotope difference between diogenites and eucrites to a magmatic process, whereby extensive fractionation of mafic minerals (olivine and orthopyroxene) with light $\mathrm{Mg}$ from a (very) large degree melt of vestan mantle produced progressively heavier $\mathrm{Mg}$ isotopes in the residual (eucritic) magma.

A study of basaltic samples from the Kileaua Iki lava lake on Hawaii (Teng et al., 2007) provide a possible upper limit on the $\mu^{25} \mathrm{Mg}$ difference between olivine and melt of $35 \mathrm{ppm}$. The analytical uncertainty of our $\mu^{25} \mathrm{Mg}$ measurements and the larger extent of mafic mineral fractionation during magma evolution on Vesta explain why changes in $\mu^{25} \mathrm{Mg}$ are detectable in HED meteorites. Further evidence of high-temperature stable $\mathrm{Mg}$ isotope fractionation between minerals and melt in different settings is shown in Figure 2. Firstly, Mg-rich olivines and surrounding quenched groundmass in the angrite meteorite NWA 1670 have a statistically significant $\mathrm{Mg}$ stable isotopic difference $\left(\mu^{25} \mathrm{Mg}\right.$ melt-olivine $=+42 \mathrm{ppm}$; Fig. 2; Schiller et al., 2015). Published data for Hawaiian basalts and their olivine phenocrysts that have stable Fe isotopes least affected by diffusion (i.e. heavy olivine Fe isotopes) also have a statistically significant difference in $\mu^{25} \mathrm{Mg}$ with $\mu^{25} \mathrm{Mg}_{\text {melt-olivine }}=+28 \mathrm{ppm}$ (Fig. 2; Teng et al., 2011 and references therein). As such, we consider that extensive mafic mineral crystallisation from a large degree partial melt represents the most viable explanation for the heavy $\mathrm{Mg}$ isotope composition of eucrites and the $\mu^{25} \mathrm{Mg}$ offset between diogenites and eucrites.

A simple model for the evolving $\mathrm{MgO}$ and $\mu^{25} \mathrm{Mg}$ in a magma undergoing olivine and orthopyroxene crystallisation is illustrated in Figure 3. This shows that $c a .45 \%$ olivine equilibrium crystallisation and $30 \%$ orthopyroxene fractional crystallisation from a $100 \%$ melt of the vestan silicate mantle will produce a melt residue with $\mathrm{MgO}$ (ca. 6 wt. \%) and $\mu^{25} \mathrm{Mg}(-64 \mathrm{ppm})$, which is comparable to that of eucrites. Although mineral-melt equilibrium isotope fractionation at high temperatures is small, only a $\mu^{25} \mathrm{Mg}_{\text {melt-olivine }}=+35 \mathrm{ppm}$ and $\mu^{25} \mathrm{Mg}_{\text {melt-orthopyroxene }}=+20 \mathrm{ppm}$ would be required to generate this isotopic fractionation (Fig. 3). Alternatively, the data can also be modelled from a parental 


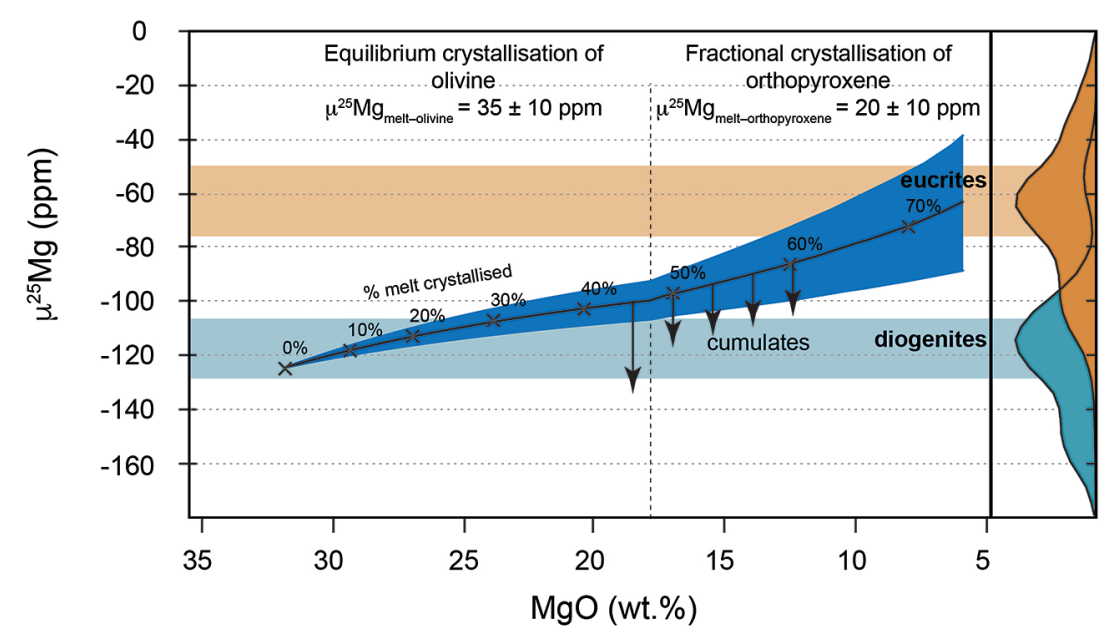

Figure 3 Modelled $\mathrm{MgO}$ and stable $\mathrm{Mg}$ isotope $\left(\mu^{25} \mathrm{Mg}\right)$ evolution of a $100 \%$ putative primary melt on Vesta (Ashcroft and Wood, 2015) of the post-core formation, vestan silicate mantle $\left(\mathrm{MgO}=31.8 \mathrm{wt}\right.$. \%). Melt-olivine $\mu^{25} \mathrm{Mg}$ fractionation of $+35 \mathrm{ppm}\left(\mu^{25} \mathrm{Mg}\right.$ melt-olivine and melt-orthopyroxene $\mu^{25} \mathrm{Mg}$ fractionation of $+20 \mathrm{ppm}\left(\mu^{25} \mathrm{Mg}\right.$ melt-orthopyroxene) can generate the heavy stable $\mathrm{Mg}$ isotopes $\left(\mu^{25} \mathrm{Mg}=-62 \mathrm{ppm}\right)$ and $\mathrm{MgO}$ contents (ca. $\left.6 \mathrm{wt} . \%\right)$ of eucrites. Olivine-orthopyroxenite cumulates generated during this process have $\mu^{25} \mathrm{Mg}$ values in the range of diogenites.

magma produced by smaller, but still very large, degrees of melting (65\%) that undergoes crystallisation (Fig. S-1b). The lighter Mg isotopic composition of olivine and orthopyroxene as compared with basaltic melt is broadly consistent with stable isotope theory (Wilding et al., 2004; Henderson et al., 2006), given that $\mathrm{Mg}$ is in six-fold and five-fold coordination in olivine-orthopyroxene crystals and silicate melts, respectively. Moreover, the high $\mathrm{MgO}$ contents of large degree melts of the vestan silicate mantle along with the lower pressure crystallisation on this protoplanet are predicted to result in even lower $\mathrm{Mg}$ coordination in vestan silicate melts than terrestrial magmas (Wilding et al., 2004).

\section{Conclusions}

Although our results cannot distinguish between a global scale or a shallow magma ocean, we consider a global scale magma ocean to be inconsistent with recent thermal models (Neumann et al., 2014) and other geochemical evidence (Barrat and Yamaguchi, 2014). Irrespective, we have shown that very large degrees of melting characterised at least parts of Vesta and that a co-magmatic relationship broadly exists between diogenites and eucrites. This study also shows that high-temperature, magmatic processes can fractionate stable $\mathrm{Mg}$ isotopes in evolving mafic magmas. With the current resolution of analytical techniques, this isotopic difference is not readily observed in igneous rocks from Earth due to the lower primary melt $\mathrm{Mg}$ contents of post-Archean igneous rocks produced at smaller degrees of melting and consequently more limited amounts of olivine crystallisation (Fig. S-1b) relative to Vesta. However, stable Mg isotope fractionations should be discernible on other rocky planets, satellites and asteroids where silicate melting was extensive and magma oceans formed and crystallised.

\section{Acknowledgements}

Financial support for this project was provided by the Royal Society of New Zealand's Marsden Fund (JB), the Danish National Research Foundation (DNRF97, MB), and the European Research Council (ERC Consolidator Grant Agreement 616027 -STARDUST2ASTEROIDS, MB). We like to thank R. Carlson and two anonymous reviewers for their constructive comments on this paper. The authors also wish to thank NASA for providing most of the meteorite samples.

\section{Editor: Bruce Watson}

\section{Additional Information}

Supplementary Information accompanies this letter at www.geochemicalperspectivesletters.org/article1703

Reprints and permission information is available online at http://www. geochemicalperspectivesletters.org/copyright-and-permissions

Cite this letter as: Schiller, M., Dallas, J.A., Creech, J., Bizzarro, M., Baker, J.A. (2017) Tracking the formation of magma oceans in the Solar System using stable magnesium isotopes. Geochem. Persp. Let. 3, 22-31.

\section{References}

AsHCROFT, H.O., WoOD, B.J. (2015) An experimental study of partial melting and fractional crystallisation on the HED parent body. Meteoritics and Planetary Science 48, 2333-2349.

BARRAT, J.A., YAMAGUCHI, A. (2014) Comment on "The origin of eucrites, diogenites, and olivine diogenites: Magma ocean crystallisation and shallow magma processes on Vesta" by B.E. Mandler and L.T. Elkins-Tanton. Meteoritics and Planetary Science 49, 468-472.

BARRAT, J.A., YAMAGUCHI, A., ZANDA, B., Bollinger, C., BOHN, M. (2010) Relative chronology of crust formation on asteroid Vesta: Insights from the geochemistry of diogenites. Geochimica et Cosmochimica Acta 74, 6218-6231.

BINZEL, R.P., XU, S. (1993) Chips off of asteroid 4 Vesta: Evidence for the parent body of basaltic achondrite meteorites. Science 260, 186-191.

Debaille, V., BRandon, A.D., YIN, Q.Z., JaCobsen, B. (2007) Coupled ${ }^{142} \mathrm{Nd}{ }^{143} \mathrm{Nd}$ evidence for a protracted magma ocean in Mars. Nature, 450, 525-528. 
Georg, R.B., Halliday, A.N., Schauble, E.A., Reynolds, B.C. (2007) Silicon in the Earth's core. Nature 447, 1102-1106.

Greenwood, R.C., Franchi, I.A., Jambon, A., Buchanan, P.C. (2005) Widespread magma oceans on asteroidal bodies in the early Solar System. Nature 435, 916-918.

HANdLeR, M.R., BAKer, J.A., Schiller, M., BennetT, V.C., YAXLeY, G.M. (2009) Magnesium stable isotope composition of Earth's upper mantle. Earth and Planetary Science Letters 282, 306-313.

Henderson, G.S., Calas, G., StebBins, J.F. (2006) The structure of silicate glasses and melts. Elements 2, 269-273.

LARSEN, K.K., SChilLER, M., BizZARRO, M. (2016) Accretion timescales and style of asteroidal differentiation in an ${ }^{26} \mathrm{Al}$-poor protoplanetary disk. Geochimica et Cosmochimica Acta 176, 295-315.

MANDLER, B.E., ElKINS-TANTON, L.T. (2013) The origin of eucrites, diogenites, and olivine diogenites: Magma ocean crystallisation and shallow magma chamber processes on Vesta. Meteoritic and Planetary Science 48, 2333-2349.

MCCORD, T.B., ADAMS, J.B., JoHnson, T.V. (1970) Asteroid Vesta: Spectral reflectivity and compositional implications. Science 168, 1445-1447.

MittlefehLDT, D.W. (2014) Asteroid (4) Vesta: I. The howardite-eucrite-diogenite (HED) clan of meteorites. Chemie der Erde - Geochemistry 75, 155-183.

Nemchin, A., Timms, N., Pidgeon, R., Geisler, T., Reddy, S., Meyer, C. (2009) Timing of 2, 133-136.

NeumanN, W., BReUER, D., SpoHn, T. (2014) Differentiation of Vesta: Implications for a shallow magma ocean. Earth and Planetary Science Letters 395, 267-280.

Pogge von Strandmann, P.A.E., Elliott, T., Marschall, H.R., Coath, C., LaI, Y.-J., JefFCOATE, A.B., IONOV, D.A. (2011) Variations of Li and Mg isotope ratios in bulk chondrites and mantle xenoliths. Geochimica et Cosmochimica Acta 75, 5247-5268.

Russell, C.T., Raymond, C.A., Coradini, A., McSween, H.Y., Zuber, M.T., Nathues, A., De Sanctis, M.C., Jaumann, R., Konopliv, A.S., Preusker, F., Asmar, S.W., Park, R.S., Gaskell, R., Keller, H.U., Mottola, S., Roatsch, T., Scully, J.E.C., Smith, D.E., Tricarico, P., Toplis, M.J., Christensen, U.R., Feldman, W.C., LaWrence, D.J., M.Coy, T.J., PretTyman, T.H., ReEdY, R.C., SYKes, M.E., Titus, T.N. (2012) Dawn at MCCOY, T.J., PRETTYMAN, T.H., REEDY, R.C., SYKES, M.E., TI
Vesta: Testing the protoplanetary paradigm. Science 336, 684-686.

Schiller, M., Baker, J.A., Creech, J., Paton, C., Millet, M.-A., Irving, A., Bizzarro, M. (2011) Rapid timescales for magma ocean crystallisation on the howardite-eucrite-diogenite parent body. Astrophysical Journal Letters 740, L22.

SCHiller, M., Connelly, J.N., Glad, A.C., Mikouchi, T., BizZARro, M. (2015) Early accretion of protoplanets inferred from a reduced inner solar system ${ }^{26} \mathrm{Al}$ inventory. Earth and Planetary Science Letters $420,45-54$.

STOLPER, E. (1977) Experimental petrology of eucritic meteorites. Geochimica et Cosmochimica Acta $41,587-611$.

TENG, F.-Z., WADHWA, M., HeLZ, R.T. (2007) Investigation of magnesium isotope fractionation during basalt differentiation: Implications for a chondritic composition of the terrestrial mantle Earth and Planetary Science Letters 261, 84-92.

Teng, F.-Z., LI, W.-Y., Ke, S., Marty, B., Dauphas, N., Huang, S., Wu, F.-Y., Pourmand, A. (2010) Magnesium isotopic composition of the Earth and chondrites. Geochimica et Cosmochimica Acta 74, 4150-4166.

Teng, F.-Z., Dauphas, N., HelZ, R.T., GaO, S., HuAng, S. (2011) Diffusion-driven magnesium and iron isotope fractionation in Hawaiian olivine. Earth and Planetary Science Letters 308, 317-324
TONKS, W B, MELOSH, HJ. (1993) Magma ocean formation due to giant impacts. Journal of Geophysical Research 98, 5319-5333.

Wang, K., Moynier, F., Dauphas, N., BarRat, J.-A., CRaddock, P., Sio, C.K. (2012) Iron isotope fractionation in planetary crusts. Geochimica et Cosmochimica Acta 89, 302-321.

Wilding, M.C., BENMORE, C.J., TANGEMAN, J.A., SAMPATH, S. (2004) Evidence of different struc tures in magnesium silicate liquids: coordination changes in forsterite- to enstatite-composition glasses. Chemical Geology 213, 281-291.

Wood, J.A., DickeY, J.S., Marvin, U.B., Powell, B.N. (1970) Lunar anorthosites. Science 167, 602-604.

XIAO, Y., TenG, F.-Z., ZHANG, H.-F., YANG, W. (2013) Large magnesium isotope fractionation in peridotite xenoliths from eastern North China craton: Product of melt-rock interaction. Geochimica et Cosmochimica Acta 115, 241-261.

Young, E.D., TonuI, E., Manning, C.E., Schauble, E., Macris, C.A. (2009) Spinel-olivine magnesium isotope thermometry in the mantle and implications for the $\mathrm{Mg}$ isotopic composition of Earth. Earth and Planetary Science Letters 288, 524-533. 